money is but a token for real wealth - a convenient method of representing its exchangeable value. These tokens cost practically nothing to produce; their value depends on the goods the exchangeable value of which they represent. Means of producing real wealth have enormously increased. There has been no corresponding method evolved by orthodox finance of insuring that, as production increases, the tokens for goods shall also increase in a like proportion.

Hence the entirely unscientific procedure of reducing the production of real wealth (in primary commodities) in order to balance an artificially restricted purchasing power due to a deficiency of tokens, and the tragic blunder of burning wheat in one country while millions are starving in another, and shipping personnel (who would gladly carry the wheat where it is wanted) are unemployed.

What is needed is surely not "salesmanship", or "to stimulate export trade between nations" (the world export trade is but an insignificant item in comparison with national trades) but a better understanding of the nature and function of money, and a scientific method of the issue of money in accordance with the ability of the community to produce all the goods which they would be glad to consume, plus a surplus which can bo exchanged (directly or indirectly) for such raw materials or specialised products as they require, but cannot produce.

In Great Britain we could easily double our present rate of goods production, and double our consumption, so as to raise the standard of material well-being of our community; we could also feed ourselves.

The present monetary systern would, however, have to be altered so that purchasing power equivalent to increased producing power was given to the community.

1, Devonshire Terrace,
Lancaster Gate, W.2.

$$
\text { R. A. S. Paget. }
$$
July 9.

WE could not possibly find space in our correspondence columns for a discussion of monetary systems; but we may say at once that we find ourselves quite unable to agree with Sir Richard Paget that planning is unscientific. Admittedly a great responsibility rests on the planners, but there is no practicable alternative at the moment to planning. In the present temper of the world, national needs have to be served first, but we must see to it also-and here science can help-that the planning is eventually international. So long as proper prices are obtained for the goods produced in Great Britain it is possible to pay satisfactory wages, salaries and dividends and so to enhance the spending power of everyone. When the goods manufactured are sold at or below the cost of pro. duction, as the result of competitive overproduction, wages and salaries are depressed to a minimum, dividends disappear, and the purchasing power of the nation sinks to mere sustenance level. We fail to understand how the production of goods below cost is the equivalent of real wealth; surely it has the contrary effect. No juggling with monetary systems will obviate this state of affairs; indeed, where the experiment has so far been tried it has not been exactly attended with success.

The Writer of the Artiche.

\section{Electrical Conductivity of Salts in Anhydrous Hydrogen Cyanide}

AN accurate determination of the conductivity of salts in anhydrous hydrogen cyanide is of considerable interest in view of the high dielectric constant of this solvent. Indications of high values for the equivalent conductance were obtained by Centnerszwer ${ }^{1}$, Kahlenberg and Schlundt ${ }^{2}$, and, more recently, by Fredenhagen and Dahmlos ${ }^{3}$. These investigators confined their measurements to relatively concentrated solutions, and came to the conclusion that hydrogen cyanide is but a poor dissociating solvent in spite of its high dielectric constant $\left(119 \text { at } 18^{\circ} \mathrm{C} \text {. }\right)^{3}$.

We have undertaken a systematic investigation of this subject, and have first determined the conductivities of a considerable number of uni-univalent salts in the concentration range $0.0001-0.005 \mathrm{~N}$, since it is in this range that the Debye-HückelOnsager equation may be tested. The preliminary measurements have been made among the chlorides, bromides, iodides, nitrates, perchlorates, thiocyanates, and pierates of lithium, sodium, potassium, ammonium, tetramethyl ammonium, and tetraethyl ammonium.

The results may be briefly summarised as follows :

Most of the salts obey tl o Kohlrausch empirical relation $\Lambda_{c}=\Lambda_{0}-x \sqrt{ } c$ over the whole concentration range investigated, and the values of $x$ found are in fair agreement with those calculated by means of the Debye-Huckel-Onsager equation.

It appears that for the alkali metal ions there is an increasing tendency to ionic association in the order $\mathrm{K} \cdot<\mathrm{Na} \cdot<\mathrm{Li}$, which is the reverse order to that in water, although, as in water and the other hydroxylic solvents, both the chlorides and nitrates of these metals show association more than the other salts.

The $\Lambda_{0}$ values have been obtained by extrapolation of the straight line portions of the $\Lambda_{c} / \sqrt{ } c$ plots. The values are about three times as great as those in water ; for example, potassium chloride in water at $18^{\circ}$ gives $\Lambda_{0}=129.8$, whilst the value in hydrogen cyanide is $363 \cdot 0$. The $\Lambda_{0}$ values are in agreement with the 'law of independent mobilities of ions', and thus support the conclusion that all the salts are almost completely dissociated at the dilutions employed :

\begin{tabular}{|c|c|c|c|}
\hline & $\mathrm{Br}^{\prime}$ & $I^{\prime}$ & $\mathrm{NO}_{3}{ }^{\prime}$ \\
\hline $\mathrm{K}$ & $363 \cdot 4$ & $364 \cdot 2$ & $353 \cdot 5$ \\
\hline $\mathrm{Na}$. & $344 \cdot 0$ & $344 \cdot 3$ & $333 \cdot 7$ \\
\hline$l_{\mathrm{K}} \cdot-l_{\mathrm{Na}} \cdot$ & $19 \cdot 4$ & $19 \cdot 9$ & $19 \cdot 8$ \\
\hline
\end{tabular}

As yet, no data are available for the calculation of the absolute mobilities of ions in hydrogen cyanide, but according to the $\Lambda_{0}$ values we may place the ions in order of increasing mobilities :

Cations : $\mathrm{Na} \cdot<\mathrm{Li}^{\cdot}<\mathrm{NEt}^{\cdot}{ }_{4}<\mathrm{K} \cdot<\left(\mathrm{NMe}{ }_{4}, \mathrm{NH}^{\cdot}{ }_{4}\right)$ Anions: Picrate $<\mathrm{NO}_{3}{ }^{\prime}<\mathrm{ClO}_{4}{ }^{\prime}<\mathrm{CNS}^{\prime}<\mathrm{Cl}^{\prime}<\mathrm{Br}^{\prime}<\mathrm{I}^{\prime}$.

A complete description of the experimental procedure, and a discussion of the results obtained, will be published elsewhere shortly.

J. E. Coates.

Chemistry Department, E. G. TAYLOR.

University College, Swansea. June 15.

1Z. Phys. Chem., 89, 220; 1902

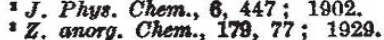

